\title{
Desempeño urbano sustentable mediante tres indicadores: residuos sólidos, transporte público, áreas verdes. Orizaba, Veracruz, México
}

\author{
Luis Gerardo Bautista Castelán \\ Pedro Martínez Olivarez \\ Monserrat Vidal Álvarez
}

Artículo

Afiliación: El Colegio de Veracruz, XalapaEnríquez, México.

E-mail: Luis Gerardo Bautista Castelán: gerardo_b_c@hotmail.com.

Pedro Martínez Olivarez:

alarife76@gmail.com.

Monserrat Vidal Álvarez:

monserrat.vidal@gmail.com

Recibido: 19 de abril del 2020

Aceptado: 29 de octubre del 2020

Luis Gerardo Bautista Castelán Licenciado en Gestión y Dirección de Negocios por la Universidad Veracruzana, Maestría en Administración y Diplomado en Administración Financiera por parte de la Universidad Latino Americana en México, actualmente pasante de la Maestría en Desarrollo Regional Sustentable en El Colegio de Veracruz.

\section{Pedro Martínez Olivarez}

Licenciatura en Arquitectura por la UNAM,

Especialidad en Educación Basada en

Competencias por la UPPue, Maestría en Valuación por la BUAP, y Doctorado en Diseño y Estudios Urbanos por la UAM-Azcapotzalco. Profesor Investigador en El Colegio de Veracruz, y consultor en planeación urbana y territorial.

\section{Monserrat Vidal Álvarez}

Ingeniería Química por el Instituto Tecnológico de Orizaba, Especialista en Diagnóstico y Gestión Ambiental por la Universidad Veracruzana, Maestría en Ciencias por el Instituto de Ecología A.C.,

Doctorado en Desarrollo Regional Sustentable en El Colegio de Veracruz. Profesor Investigador en El Colegio de Veracruz, y consultora ambiental.

\begin{abstract}
Resumen:
En el presente trabajo se pretende aproximar al lector desde una perspectiva teórica metodológica a los principios y fundamentos del desarrollo urbano sustentable al brindar un panorama general a la sustentabilidad urbana enfocada en la gestión de políticas públicas sustentables. En este sentido el trabajo presenta un análisis crítico del caso de la ciudad de Orizaba, Veracruz, México. Ha sido catalogada dentro del Índice de Ciudades Prósperas de la ONU (CPI) como una ciudad sustentable a partir de diversas medidas. Sus resultados en políticas urbanas han sido enfocados en tres indicadores urbanos específicos: gestión de residuos sólidos, transporte público eficiente, y gestión de áreas verdes. Si bien el trabajo no recurre a un ejercicio estadístico, metodológicamente se aborda una revisión y análisis de los instrumentos informativos de carácter público de dicha ciudad que corresponden a los indicadores anteriormente mencionados. De esta manera, se tiene como propósito generar una discusión reflexiva sobre la aplicación de los instrumentos de evaluación y certificación que catalogan a las zonas urbanas como sustentables o no, para contrastarlos con la realidad de la situación actual de la ciudad.
\end{abstract}

Palabras clave: Indicadores, políticas públicas, sustentabilidad urbana.

Sustainable urban performance through three indicators: solid waste, public transportation, green areas. Orizaba, Veracruz, Mexico

\section{Abstract:}

The present work aims to bring the reader closer to the principles and foundations of sustainable urban development from a theoretical-methodological perspective, providing an overview of urban sustainability through a series of antecedents and references focused on the management of sustainable public policies. In this sense, the work presents a critical analysis of the case of the city of Orizaba, Veracruz, Mexico; It has been cataloged within the UN Prosperous Cities Index (CPI) as a sustainable city, based on implemented measures and their results in urban policies focused on three specific urban indicators: solid waste management, efficient public transport, and management of green areas. Although the work does not resort to a statistical exercise, methodologically a review and analysis of the public information instruments of said city that correspond to the aforementioned indicators is addressed, thus having the purpose of generating a reflective discussion on the application of the evaluation and certification instruments that classify urban areas as sustainable or not, contrasted with the reality of the current situation in the city.

Keywords: Indicators, public policies, urban sustainability. 


\section{Introducción}

n los últimos años la sustentabilidad urbana, se ha convertido en uno de los temas de mayor recurrencia y relevancia dentro de las agendas internacionales para con las ciudades. Algunos ejemplos de estos compromisos son Aarlborg de la Campaña de las Ciudades Europeas Sostenibles en 1994, en 1996 con la Declaración de Santa Cruz de la Sierra de los ministros de medio ambiente de la OEA (Organización de los Estados Americanos), en la Declaración de Hong Kong de 2005 firmada por representantes de ciudades de Asia y más recientemente la Agenda 2030 para el Desarrollo Sostenible de la ONU elaborado por la Asamblea General de las Naciones Unidas (Barton, 2016). Las problemáticas generadas por la alta concentración de gran parte de la población mundial en zonas urbanas se han magnificado, actualmente más de la mitad de la población mundial vive en zonas urbanizadas, en América Latina 8 de cada 10 personas habita en ciudades y se espera que para el 2050, dos tercios de la población mundial sea urbana (ONU, 2018).

El Reporte Mundial de Ciudades 2016, señala que entre las problemáticas urbanas más persistentes se encuentran: el crecimiento urbano, el creciente número de personas viviendo en las periferias en asentamientos informales, así como el proveer servicios urbanos óptimos y de calidad para todos. Lo anterior, genera una fuerte presión demográfica sobre el planeta y los recursos naturales, debido principalmente a la falta de planificación territorial, urbana y ecológica, lo que crea una sobre explotación del territorio. Así, se tiene un territorio que, a nivel global, ha ido quedando marcado por problemas que son similares en muchas de las ciudades y que contribuyen a la insostenibilidad urbana, entre ellos: la congestión vehicular, la falta de áreas verdes y la continua sobre explotación de los servicios de limpieza pública.

Dada la importancia de atender estas y otras problemáticas, en la conferencia Hábitat III de 2016, representantes gubernamentales y sociales de diferentes países crearon un mapa de ruta orientado a lograr que las ciudades y los asentamientos humanos sean inclusivos, seguros, resilientes y sostenibles. Estos principios urbanos adherentes a la Nueva Agenda Urbana, ello, haciendo uso de investigaciones e información proporcionada por instituciones asociadas de todo el mundo; complementando con aportaciones de expertos internacionales y la experiencia de la Organización de las Naciones Unidas para la Educación, la Ciencia y la Cultura (UNESCO por sus siglas en inglés). El Informe Mundial generó recomendaciones para apoyar el diseño de políticas y estrategias operativas en torno a la sustentabilidad urbana. Así, temas como la gestión de residuos sólidos, transporte público eficiente, y gestión de áreas verdes municipales, pueden constituirse en la columna vertebral de un modelo urbano encaminado a un futuro sustentable que contenga ciudades con equidad en torno al acceso y provisión de los servicios y equipamientos básicos tratando de aprovechar mejor los recursos, reducir la contaminación y la pobreza urbana.

Es importante reconocer que la gestión y aplicación de políticas públicas en torno a la sustentabilidad urbana no consiste solamente en replicar políticas que resulten eficientes en escenarios variados. La eficacia de las reformas políticas necesarias en el proceso de aplicación requiere de acciones y cambios centrados en las necesidades de la zona en donde serán aplicadas. Dicha eficacia depende de la existencia de instituciones públicas sólidas y transparentes a nivel nacional e internacional para que sean aplicadas y calificadas de acuerdo a su grado de impacto y efectividad. Es decir, así como resulta de poca utilidad calificar con los mismos criterios de sustentabilidad una región con más de ocho millones de habitantes (como lo es la ciudad de México) y a una ciudad con ciento veinte mil habitantes (como lo es la ciudad de Orizaba, Veracruz, México), tampoco será útil la aplicación de políticas públicas en dos localidades con diferentes fortalezas, oportunidades, debilidades, y amenazas (FODA).

Dicho lo anterior, no se pretende señalar que realizar una medida estadística no resulte instructiva y no genere la oportunidad de visualizar un panorama generalizado de las posibles alternativas en torno a las necesidades de una zona. Sin embargo, lo que este trabajo propone es que un estudio como el Índice de Ciudades Prósperas de la ONU, requiere de métodos evaluativos específicos para la realidad local, que, además de prácticos y constantes, permitan evaluar y dar seguimiento a las fluctuaciones medidas 
para que, por lo menos en el caso de estudio, pueda señalarse si la acreditación de sustentabilidad es realmente vigente.

\section{La representación de las acciones a través de dimensiones e indicadores}

Partiendo de la conceptualización de ciudad sustentable, Ruiz (2011) menciona que ésta debe de contar con cuatro dimensiones principales: sostenibilidad ambiental, desarrollo urbano, sostenibilidad económica y sostenibilidad de gobernanza. En esta tesitura, la primera de estas dimensiones debe atender a la gestión y manejo de los recursos naturales que se encuentran a su cuidado, por lo que una ciudad con un correcto sistema de sostenibilidad ambiental cuida y procura la remisión de los gases contaminantes que se generan por sus habitantes. De esta manera, atiende a la mitigación y adaptación paulatina de los efectos negativos generados por el cambio climático. En otras palabras, una ciudad con principios de sostenibilidad cuida las relaciones socioeconómicas que se establecen con el medio ambiente para que estas no lleven a su destrucción, de modo que, dichas relaciones, sean perdurables y sustentables a largo plazo (Quiroz, 2018).

Respecto a la dimensión de desarrollo urbano, una ciudad sustentable tiene en vigor políticas actualizadas de crecimiento demográfico que controlan su expansión. Gracias a la gestión de un adecuado programa de ordenamiento territorial, una ciudad sustentable genera un cambio estructural positivo en los asentamientos humanos urbanos que garantizan la conservación ambiental. Lo anterior incentiva a empresas a que realicen inversiones económicas locales, sin dejar de lado la dignificación de la vida de sus habitantes, al proporcionar servicios básicos que garanticen un nivel de vida adecuado (Hernández, 2019).

La dimensión de sostenibilidad económica se refiere al hecho de promover el enriquecimiento local mediante un desarrollo mercantil propio. Una correcta sustentabilidad económica se logra a través de una economía donde se generen condiciones para posibilitar la productividad y la competitividad entre y para sus mismos habitantes, además de asegurarse de generar un crecimiento de capital equitativo, que beneficie y brinde a la población las oportunidades para la plenitud de su vida (Azuero, 2013).

Finalmente, respecto a la dimensión de gobernanza, esta refiere a un gobierno ciudadano que respalde los puntos anteriores, es decir, que sus decisiones, políticas y acciones cuenten con el respaldo de la razón y de los gobernados para alcanzar en conjunto la plenitud de las iniciativas. Esto con el fin de que dichas premisas se fomenten dentro de la ciudad, así como los objetivos propuestos, se trata de un gobierno cuyos beneficios pueden mantenerse y extenderse perpetuamente en el tiempo sin que se vuelvan contra él (Viso, 2005). En términos generales, debe procurarse un crecimiento ordenado que lleve a la sustentabilidad, puesto que una ciudad desordenada en su crecimiento arrastra su propio deterioro (Satterthwaite, 1993), y para ello habrá que saber que a través de los indicadores ambientales se puede dar seguimiento no solo al impacto humano sobre el ambiente, sino a las acciones biofísicas y socioeconómicas que determinan la sustentabilidad de una ciudad. Al respecto Rodríguez y Flores señalan que:

Los indicadores ambientales deben, como su nombre lo sugiere, indicar o dar a entender algo con indicios o señales sobre algún aspecto del ambiente. No existe una definición única de los indicadores ambientales, sino una amplia lista que responde a los objetivos para los cuales han sido creadas 0 , simplemente, a las instituciones que las presentan. (2009, p. 16)

En los últimos años la preocupación del impacto insostenible de las ciudades ha tenido enormes resultados y aportes para el desarrollo de indicadores. Específicamente en países como Canadá y otros pertenecientes al continente europeo durante la década de los ochentas generaron e implementaron indicadores propios para propósitos de desarrollo sustentable; Latinoamérica inició la utilización de estos indicadores una década después (CEPAL, 2007). Cada país, estado, departamento, municipio o alcaldía, 


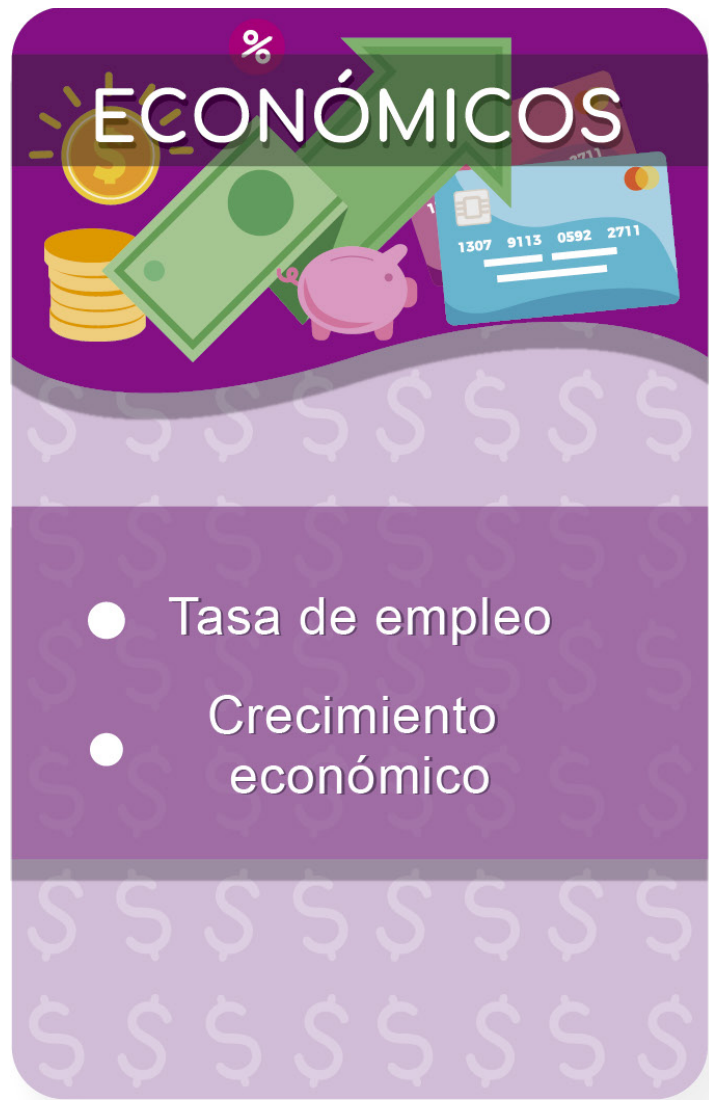

Figura 1. Indicadores y subindicadores de sustentabilidad para México.

Fuente: Elaboración propia con información de INEGI (2018). puede generar sus propios indicadores con ayuda de su institución correspondiente, en el caso de México, los indicadores implementados están construidos a través del Instituto Nacional de Estadística y Geografía, INEGI (2018) (Figura 1).

Los indicadores pretenden ser una herramienta para los planificadores, gestores y políticos de la ciudad, que pueden medir y evaluar el impacto socioeconómico y ambiental que tienen las acciones que en rubro urbano se realizan. Para poder medir y evaluar esos impactos a manera de niveles de sustentabilidad, los indicadores cuentan con criterios cuyo carácter puede ser cuantitativo y/o cualitativo. En este sentido, los indicadores cuantitativos corresponden al valor registrado como indicador de un sector de análisis, el cual es comparado y evaluado en relación a su grado de impacto. Este puede ser analizado acorde a diversos tipos de normas, criterios de temporalidad y evaluación regional, por otra parte los indicadores cualitativos se basan principalmente en la gestión, vigencia y/o pertinencia de políticas y estrategias ambientales establecidas en las distintas instituciones públicas y privadas correspondientes a los sectores de análisis (SEMARNAT, 2020).
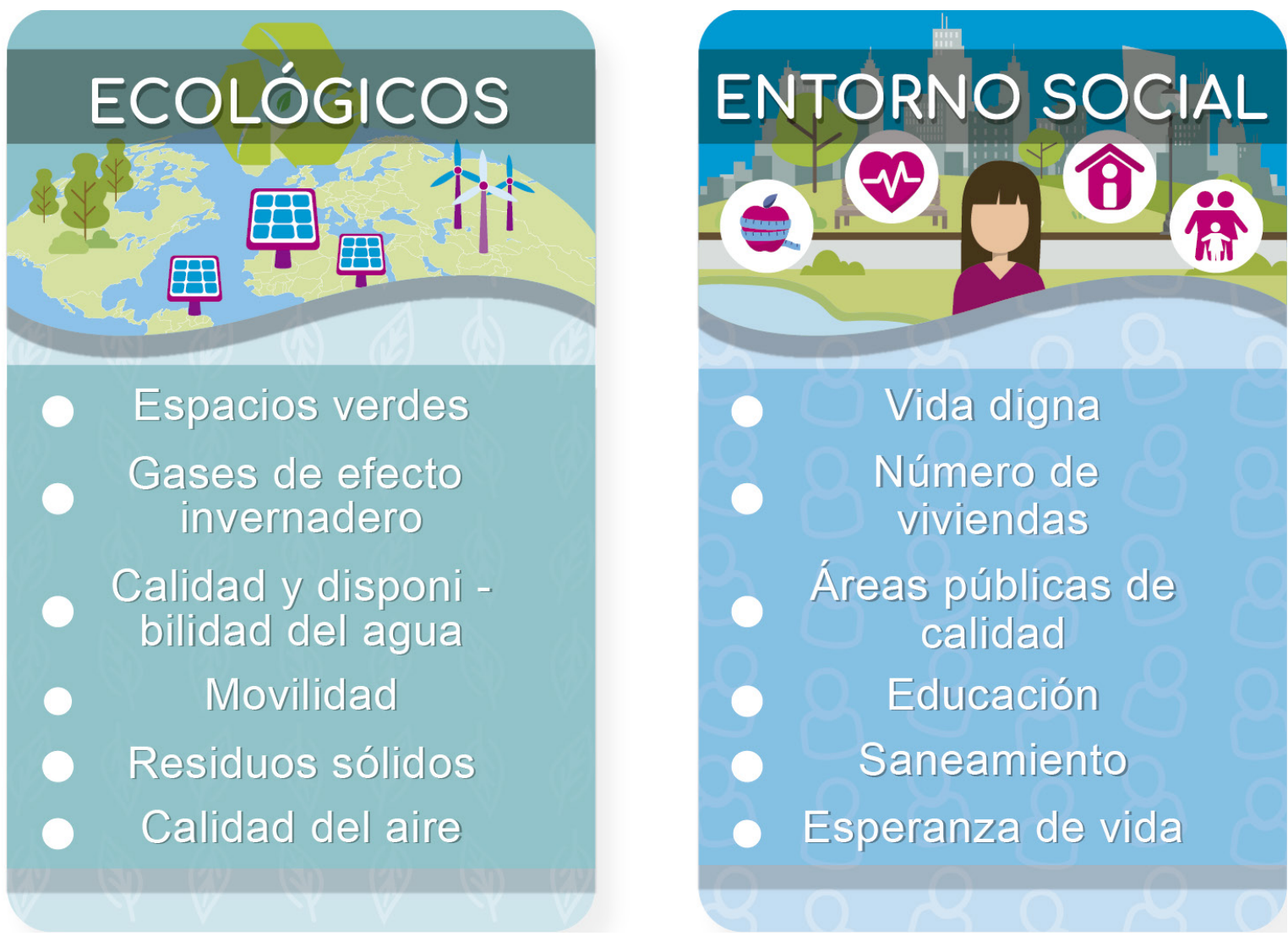

De esta manera, los indicadores de sustentabilidad permiten cubrir el objetivo de simplificar, cuantificar y evaluar fenómenos complejos, como los biofísicos producto del resultado de acciones de planificación y, que constituyen, por lo tanto, una fuente de información y análisis para la toma de decisiones. Pero para ello y según Baca (2014), debe definirse una escala de evaluación que a manera de escala de apreciación pueda adaptar los valores según las representaciones de las acciones locales, así, la evaluación de una variable urbana se basa en el desempeño de los diferentes indicadores en materia de política urbana que se implementan para alcanzar el rango de ciudad sustentable.

\section{Gestión integral de planificación y políticas urbanas}

La planificación urbana se ha convertido en uno de los instrumentos de materialización tanto del desarrollo urbano como el humano, sin embargo, esta no se encuentra exenta de fallos técnico-institucionales. Para resultados más eficaces es necesario incluir mecanismos que coadyuven a la mejora de resultados en cuanto a las políticas públicas, ya que es a través de ella que se plantean, pero deben de ser enfocadas al servicio de la sociedad y el medio ambiente. En este sentido, la gobernanza y la participación ciudadana juegan papeles fundamentales para dinamizar una forma de construcción colectiva de la ciudad y de gestión integral de las políticas urbanas. Se toma como base las opiniones de quienes habitan en las ciudades en conjunto con las autoridades y demás organizaciones, sin analizar que cada escenario que presenta una falta de política de planificación sustentable tiene su origen en una falta de planificación ciudadana (Apablaza y Ruiz, 2010) (Figura 2). 


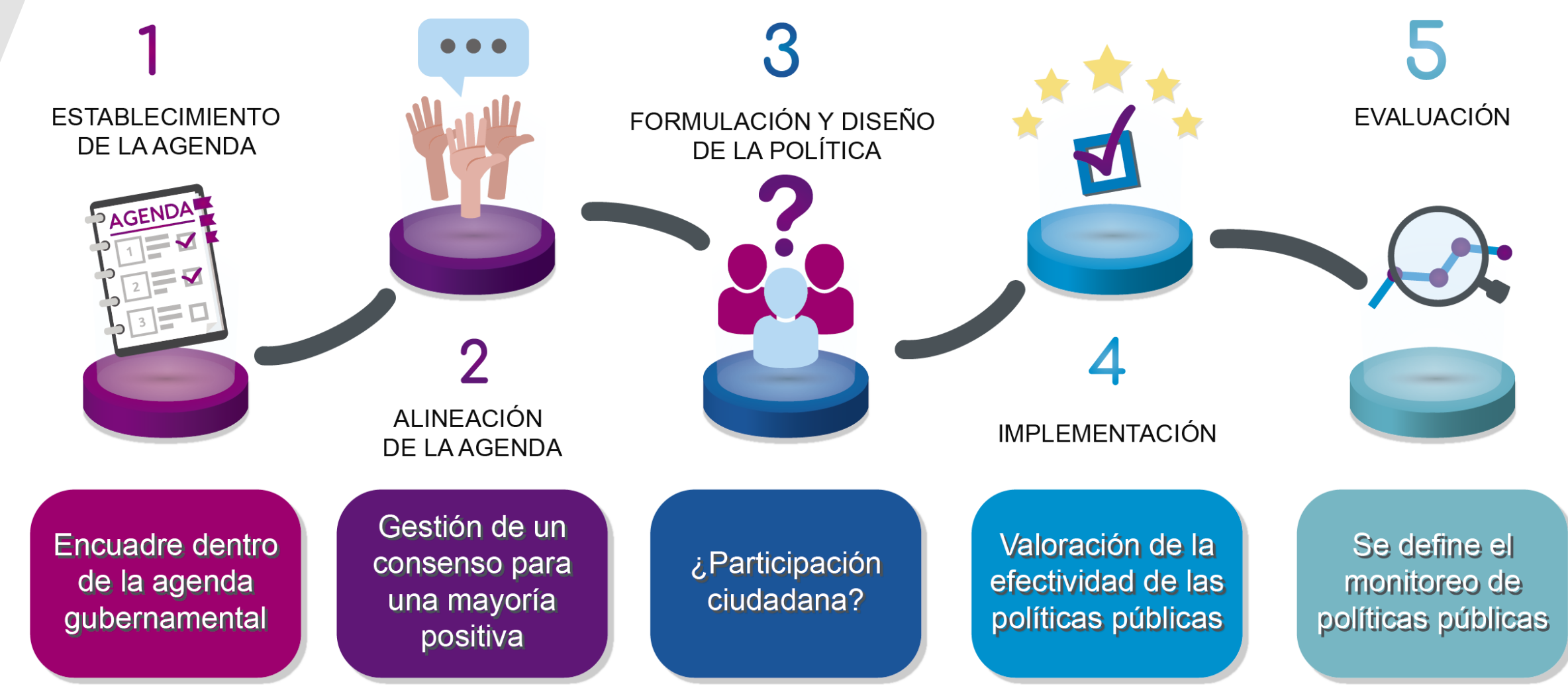

Figura 2. Proceso de gestión integral de la política pública en México.

Fuente: Elaboración propia con información de Rodríguez (2015).
A Esta forma de planificar a través de la cooperación entre el gobierno y otros actores refiere a una capacidad mayor de influencia que los actores no gubernamentales (actores como empresas, sociedades civiles, organismos no gubernamentales, y organismos financieros de impacto nacional) han alcanzado para tener voz y voto dentro de los asuntos políticos. Así, lo que resulta es una gestión integral de las políticas urbanas mediante una serie de mecanismos, procesos, relaciones e instituciones por medio de los cuales los ciudadanos articulan sus intereses, ejercen sus derechos y obligaciones y median sus diferencias (Norris, 2002), mecanismos que, a la luz del ejercicio de planificación urbana, contribuyen a la materialización de la ciudad sustentable.

No está de más decir que durante el 2008 en México 17 estados ya contaban con una ley de participación ciudadana, es decir el 53\% del territorio nacional. De estos 17 estados, cada uno optó por una medida de participación específica, en otras palabras, no todas las medidas de participación fueron iguales. Esto se debió al interés y la exigencia de los individuos sociales para inferir en la toma de decisiones: 16 de ellos contaban con la iniciativa popular, 7 con la consulta ciudadana, 5 con la colaboración ciudadana, 4 con la difusión pública, 5 con la audiencia pública; 3 con recorridos del presidente municipal; 1 con la asamblea ciudadana, 2 con la revocación de mandato, y 1 con la rendición de cuentas (González y Maldonado, 2008).

Aun así, pese a que los programas de participación se encuentran ya en vigor, permanecen en un estado de aletargamiento. Esto se debe en gran medida a que, si bien existe un número de personas que participan activamente en los asuntos públicos, hay una cantidad mucho mayor que no está interesada en esas cuestiones. La participación es más activa en la evaluación de los programas sociales y de las políticas públicas. Sin embargo, tampoco son muy exitosos porque muchos de ellos son abandonados 0 suspendidos por la administración siguiente, dejando inconclusa la obra de evaluación y por ende de retroalimentación (Olvera, 2007).

\section{Índice de Ciudades Prósperas}

El Índice de las Ciudades Prósperas (CPI, por sus siglas en inglés) forma parte de la Iniciativa de las Ciudades Prósperas, diseñado por ONU-Habitat. Constituye una herramienta de medición para identificar oportunidades y debilidades en las zonas urbanas, con ello se genera una herramienta de apoyo para la toma de decisiones en aspectos de políticas públicas en los diferentes niveles y dependencias de gobierno. Esta herramienta también es tomada como punto de referencia para que ciudades organicen y prioricen sus proyectos en torno a una mejora sustentable dentro de su territorio.

El CPI es tomado en cuenta para el desarrollo de muchas zonas urbanas ya que su enfoque se torna hacia la sustentabilidad, es decir, promueve un modelo de 
Figura 3. Indicadores y respectivos subindicadores que componen el Índice de Ciudades Prósperas.

Fuente: ONU (2018) urbanización sostenible universal, tomando en cuenta una generalidad de necesidades y particularidades en sus indicadores; así, el análisis de 6 dimensiones y 20 subdimensiones estudia la articulación general de una multiplicidad de fenómenos que van desde lo económico, lo institucional, el aspecto social y aspecto ecológico. De esta manera permite entregar información resumida para los dirigentes de una localidad que promueva la toma correcta de decisiones (Figura 3).

\begin{tabular}{|c|c|c|}
\hline Dimensión & Subdimensión & Indicador \\
\hline \multirow[t]{5}{*}{ Productividad } & Crecimiento económico & Producto urbano per cápita \\
\hline & & Relación de dependencia de la tercera edad \\
\hline & Aglomeración económica & Densidad económica \\
\hline & Empleo & Tasa de desempleo \\
\hline & & Relación empleo-población \\
\hline \multirow{12}{*}{$\begin{array}{l}\text { Infraestructura de } \\
\text { desarrollo }\end{array}$} & Infraestructura de vivienda & Vivienda durable \\
\hline & & Acceso a agua mejorada \\
\hline & & Espacio habitable suficiente \\
\hline & & Densidad poblacional \\
\hline & Infraestructura social & Densidad de médicos \\
\hline & Infraestructura de comunicaciones & Acceso a internet \\
\hline & & Velocidad de banda ancha promedio \\
\hline & Movilidad urbana & Longitud de transporte masivo \\
\hline & & Fatalidades de tránsito \\
\hline & Forma urbana & Densidad de la interconexión vial \\
\hline & & Densidad vial \\
\hline & & Superficie destinada a vias \\
\hline \multirow[t]{7}{*}{ Calidad de vida } & Salud & Esperanza de vida al nacer \\
\hline & & Tasa de mortalidad de menores de cinco años \\
\hline & Educación & Tasa de alfabetización \\
\hline & & Promedio de años de escolaridad \\
\hline & Seguridad y protección & Tasa de homicidios \\
\hline & Espacio público & 'Accesibilidad al espacio público abierto \\
\hline & & 'Áreas verdes per cápita \\
\hline \multirow{6}{*}{$\begin{array}{l}\text { Equidad e } \\
\text { inclusión social }\end{array}$} & Equidad económica & Coefiiciente de Gini \\
\hline & & Tasa de pobreza \\
\hline & Inclusión social & Viviendas en barrios precarios \\
\hline & & Desempleo juvenil \\
\hline & Inclusión de género & $\begin{array}{l}\text { Inscripción equitativa en educación de nivel } \\
\text { secundario }\end{array}$ \\
\hline & Diversidad urbana & Diversidad en el uso de suelo \\
\hline \multirow[t]{6}{*}{ Sostenibilidad ambiental } & Calidad del aire & Número de estaciones de monitoreo \\
\hline & & Concentraciones de material particulado \\
\hline & & Concentración de $\mathrm{CO}_{2}$ \\
\hline & Manejo de residuos & Recolección de residuos sólidos \\
\hline & & Tratamiento de aguas residuales \\
\hline & Energía & Proporción de generación de energía renovable \\
\hline \multirow[t]{5}{*}{ Gobernanza y legislación } & Participación y rendición de cuentas & Participación electoral \\
\hline & Capacidad institucional y finanzas municipales & Recaudación de ingresos propios \\
\hline & & Deuda subnacional \\
\hline & & Eficiencia del gasto local \\
\hline & Gobernanza de la urbanización & Eficiencia en el uso de suelo \\
\hline
\end{tabular}


Figura 4. Escala de prosperidad urbana, niveles > de medición y niveles de intervención.

Fuente: ONU (2018)
Figura 5. Tabla comparativa del año 2014 con respecto al 2017 en indicadores seleccionados. Fuente: Elaboración propia con información de ONU (2018).

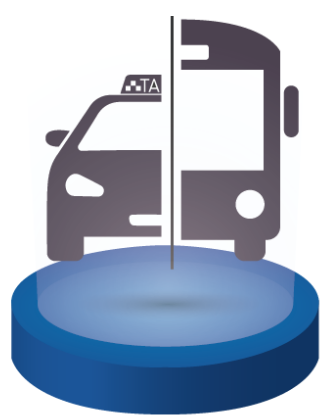

TRANSPORTE PÚBLICO
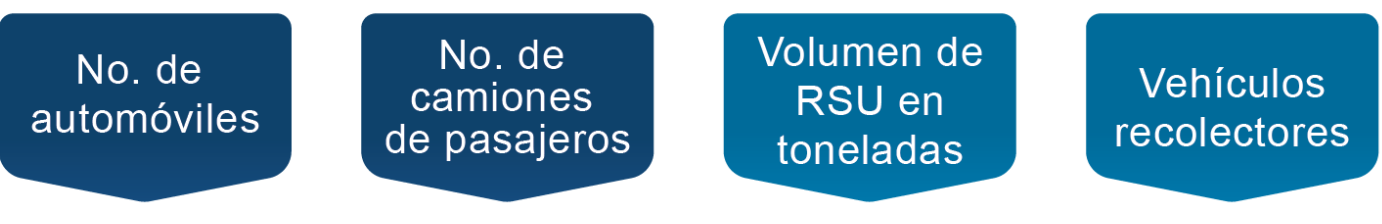

RESIDUOS SÓLIDOS

Todo esto logrado gracias al apoyo del Fondo Nacional de la Vivienda para los Trabajadores (INFONAVIT) y a la Secretaría Desarrollo Agrario, Territorial y Urbano (SEDATU) que proporcionan información estadística oficial por medio de la cual este informe se conforma. El cálculo del CPI aporta información para la comprensión de la realidad urbana y socio-geográfica de los 305 municipios con medición del CPI básico. Sin embargo, a excepción de los indicadores cuya base de cálculo se determina a partir de su configuración urbana, esta medición se soporta fundamentalmente en información municipal (ONU, 2018).

\section{Acercamiento metodológico y empírico del estudio de caso: Orizaba, Veracruz, México}

Como se mencionó anteriormente, el abordaje de este documento tiene propósitos explicativos o aclaratorios, analizando la implementación de políticas públicas en torno a la sustentabilidad urbana y su acreditación como una ciudad sustentable; tomando como caso de estudio la ciudad de Orizaba en el estado de Veracruz, México, con el fin de que se tome conciencia de la situación geográfica, económica, poblacional, entre otras, que tienen estos municipios nacionales mexicanos y se puedan incidir en el futuro en la gestión integral de las políticas urbanas. A continuación, se analizarán los indicadores de transporte público, áreas verdes y limpieza pública de la cuidad desde las experiencias instrumentalistas, analizando el Plan Municipal de Desarrollo (PMD 2014-2017), las normativas vigentes y su comparación con los resultados obtenidos por la ONU (2018) de la ciudad (Figura 5).
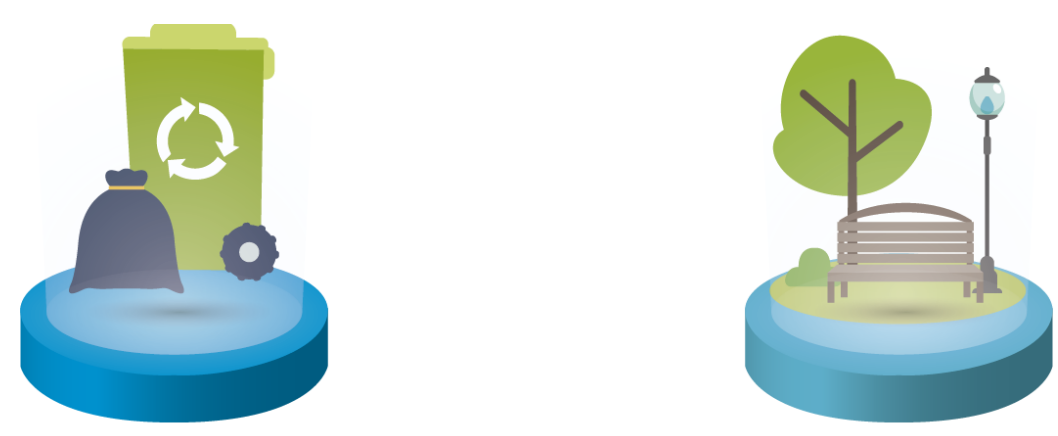

ÁREAS VERDES

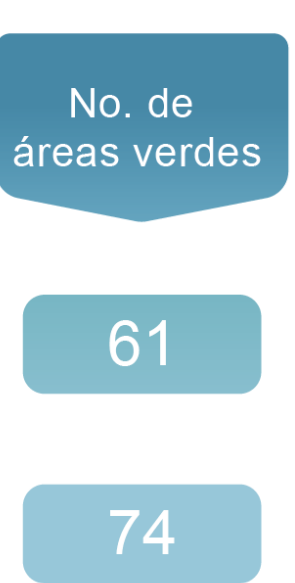


Es importante mencionar que estos indicadores fueron seleccionados para su estudio debido a que, si bien cada urbanización cuenta con sus propias fortalezas y necesidades en el ámbito sustentable, los indicadores de residuos sólidos, áreas verdes y transporte público, son factores que podemos encontrar casi en cualquier zona urbana. Es por ello por lo que se retoman estos resultados, tanto por la pertinencia de estos indicadores como por su adaptabilidad a los entornos analizados en el CPI nacional.

Es así, como el esquema de desarrollo de la ciudad ha causado interés por el análisis de sus acciones políticas-sustentables desde las propuestas implementadas en el PMD 2014-2017 hasta la puesta en marcha de acciones específicas para el progreso de la ciudad. En términos de la administración pública se investigaron cuáles han sido las acciones tomadas por sus gobernantes en los temas de gestión de residuos sólidos, transporte público y áreas verdes, para encaminarlas hacia el cumplimiento de las pautas sustentables, y cómo ha reaccionado la ciudadanía en estos temas tanto en la eficacia de estas como en la aceptación y cumplimiento de las normativas (Orizaba, 2014).

A continuación, se expone una breve introducción a la zona de estudio, así como el desarrollo individual en cuanto a los tres indicadores seleccionados.

Ubicación geográfica del estudio de caso:

La ciudad de Orizaba se encuentra ubicada en la zona centro montañoso del estado de Veracruz, sobre el valle del Pico de Orizaba, a una altura de 1,230 metros sobre el nivel del mar. Su clima es templado-húmedo-regular con una temperatura promedio de $18^{\circ} \mathrm{C}$ y su precipitación pluvial media anual es de $1,800 \mathrm{~mm}$. Los ecosistemas que coexisten en el territorio del municipio que la alberga son el de bosque frío de pináceas donde se desarrolla una fauna compuesta por poblaciones de conejos, tlacuaches, mapaches, ardillas, zorras, comadrejas y aves. Además, cuenta con "El Citlaltépetl" conocido comúnmente como "Pico de Orizaba" que es la montaña más alta de México y que fue decretada como Área Natural Protegida (ANP). Su distancia aproximada con la capital del estado por carretera es de $190 \mathrm{Km}$, y junto con otros municipios aledaños forma la cuarta zona metropolitana más poblada de la entidad veracruzana, además, en el año 2015 fue nombrada "Pueblo Mágico", el cual, es un reconocimiento otorgado por la Secretaría de Turismo (SECTUR) de México que destaca ciudades o poblados por su labor en proteger y guardar su riqueza natural y cultural (Figuras 6 y 7).

La ciudad de Orizaba cuenta con 120,995 habitantes (sin contar la zona metropolitana) y fue el primero de los laboratorios urbanos que en materia de desarrollo sostenible se generaron en México. Esto con el fin de impulsar una economía sana, con desarrollo incluyente y visión sostenible, de acuerdo con la Agenda 2030. Para ello, se creó un Consejo Municipal para el Cumplimiento de la Agenda 2030, el cual, tiene como objetivo impulsar políticas públicas dentro de los programas municipales y sectoriales acordes al Plan Nacional de Desarrollo y a los Objetivos del Desarrollo Sostenible de ONUHABITAT (Hernández, 2019). En este contexto, la ciudad de Orizaba, está posicionada como una de las 10 ciudades más sustentables de México, ya que, según cifras expuestas por el ONU (2018), la población goza de bienes y servicios comunitarios derivados de una buena planeación urbana, lo cual, genera las condiciones necesarias para proporcionar a sus habitantes una calidad de vida digna, es decir, bienestar social.

Por otro lado, es importante mencionar que en la ciudad de Orizaba debido a la contingencia sanitaria causada por el Covid-19, se decretó desde el 16 de marzo del 2020 la jornada de sana distancia, que, a nivel nacional, consiste en la limitación de las actividades regulares y solo se permitía el desarrollo de las estrictamente necesarias, es decir, aquellas relacionadas con salud y bienestar de la sociedad (Navarro, 2020). Por lo anterior, el levantamiento de datos se vio modificado y adaptado. Además, resulta relevante aclarar que los resultados se ven comprometidos si se comparan con una situación de cotidianidad ciudadana. Aun así, con los resultados observados se pueden comparar y analizar ambas deducciones.

Dentro de esta adaptación en la metodología del levantamiento de datos, se realizó un ejercicio de observación individual en algunas zonas de la ciudad de Orizaba, Veracruz (Figura 6). Dicha observación se sistematizó en una bitácora diaria la cual se dividió en: 26 días continuos para el transporte público y 15 días salteados para el servicio de 


\section{MUNICIPIO DE ORIZABA,VERACRUZ,MEXICO}

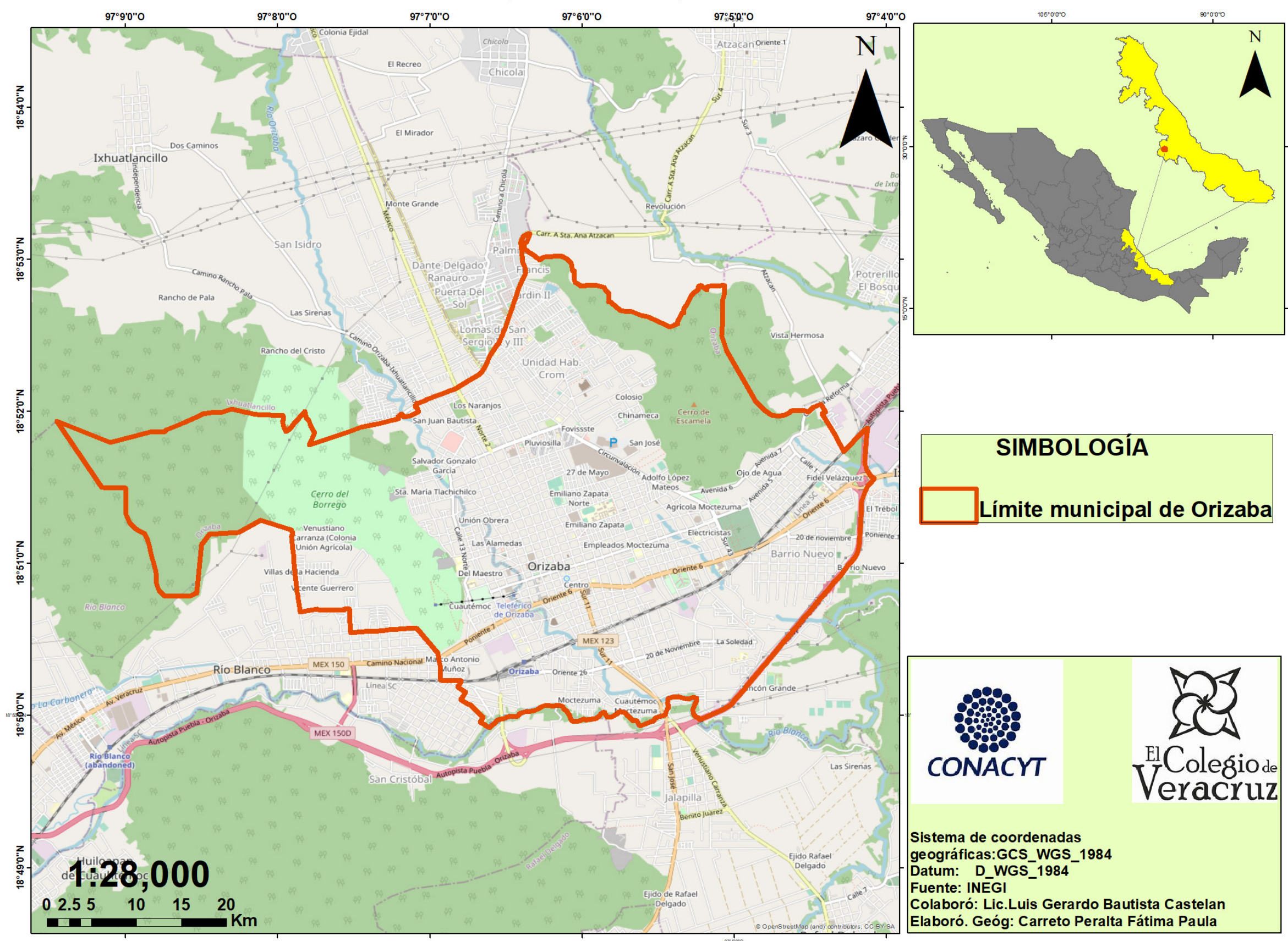

Figura 6. Mapa de la ubicación geográfica de municipio y la ciudad de Orizaba, Veracruz, México.

Fuente: Elaborado por Carreto Peralta Fátima Paula con información de INEGI (2018).

Figura 7. Imagen panorámica de la ciudad de Orizaba, Veracruz, México.

Fuente: Tomada de Jardinez (2019).

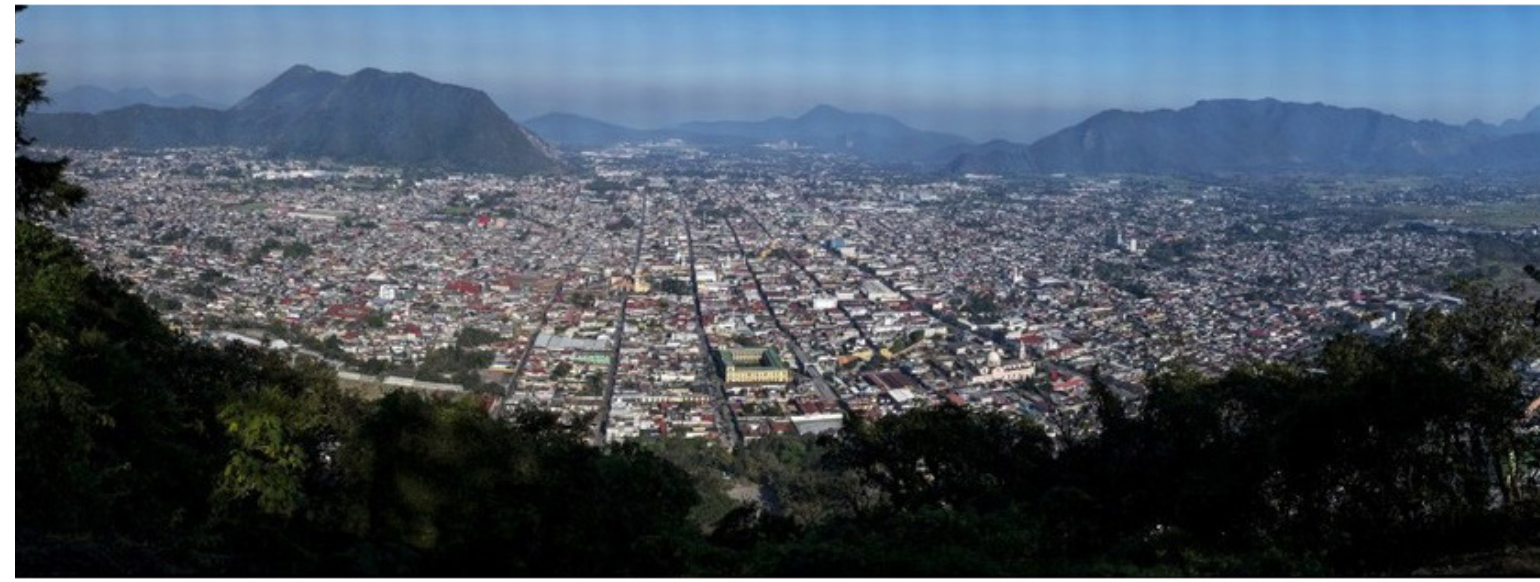

limpieza pública, debido a que el servicio municipal se ofrece 4 veces por semana y 1 ejercicio de observación único para las áreas verdes debido al cierre de parques y zonas públicas a nivel nacional. Se midieron factores claves que califica el CPI de la ciudad en su última versión 2018 en sus indicadores relacionados con residuos sólidos y transporte público. El objetivo de este ejercicio fue contrastar los resultados observados vivencialmente en la ciudad con la calificación obtenida en estos indicadores según el CPI indicado.

Así, este esquema de desarrollo de la ciudad ha provocado el interés por el análisis de sus acciones políticas-sustentables, desde las propuestas implementadas en el PMD 2014-2017, hasta la puesta en marcha de acciones específicas para el progreso de la ciudad. En términos de la administración pública, se investigaron cuáles han sido las acciones tomadas por sus gobernantes en los temas de gestión de residuos sólidos, transporte público, y áreas verdes, para encaminarla hacia el cumplimiento de las pautas sustentables. También, tiene como fin explorar cómo ha sido la respuesta y aceptación ciudadana en estos temas en la sociedad. A continuación, se expone el análisis de los instrumentos analizados en cuanto a los tres indicadores seleccionados: 
En cuanto a la gestión de residuos sólidos:

En la ciudad de Orizaba, mediante programas municipales coordinados por la Dirección de Limpia Pública de la ciudad, se gestionaron, desde el año 2014, proyectos enfocados a la recolección, clasificación y comercialización de aquellos residuos que puedan ser reutilizados. El manejo de los residuos que genera la ciudad representó una prioridad para las autoridades municipales desde su propuesta en el PMD. Una de las prioridades para el ayuntamiento fue la puesta en marcha de programas de separación y generación de utilidades derivados de los residuos sólidos municipales (RSM), siendo este uno de los rubros más productivos con fines de reciclaje.

Asimismo, en la ciudad de Orizaba, se implementaron estrategias sobre la concientización de sus habitantes para la separación de la basura dentro del hogar (siendo obligatoria esta separación para que el sistema de limpieza pública de la cuidad cumpliera con el servicio dentro de las unidades habitacionales) y de esta manera facilitar la recolección de forma ordenada de sus residuos orgánicos e inorgánicos. El municipio inició ofreciendo el retiro de sus residuos 3 veces por semana, siempre y cuando estuvieran separados y organizados. Por otro lado, el ciudadano obtenía beneficios económicos derivados del pago de limpieza pública habitacional y comercial, ofreciendo hasta un $30 \%$ de descuento para el pago del impuesto predial (el cual es un gravamen anual sobre una propiedad o posesión inmobiliaria) al precio final. Es decir, de esta manera asegura la participación y el apoyo constante de sus habitantes para la optimización del servicio de limpieza pública del municipio, y a su vez, facilita las labores de los empleados de este servicio (Ayuntamiento de Orizaba, 2018).

En la actualidad, los desechos sólidos inorgánicos recolectados son utilizados para su separación y reciclaje, mientras que la materia orgánica es dispuesta para la elaboración de composta. El municipio recolecta actualmente más de 3,000 toneladas de RSM de manera mensual, y, con las acciones tomadas, solo se destina un $10 \%$ de estos residuos para el relleno sanitario. Lo más importante es que con estas medidas, temas como el mantenimiento de la ciudad dejan de ser un factor unilateral por parte del municipio, pues hacen participe al ciudadano en el cuidado para propiciar el mantenimiento general desde la comunidad (SEFIPLAN, 2019). Dentro de las ventajas de estas medidas, se encuentran la mejora del medio ambiente, disminución de la cantidad de residuos que se llevan a los rellenos sanitarios, concientización hacia el medio ambiente, disminución de costos por la recolección y manejo de residuos.

La evaluación realizada en el CPI de Orizaba mide la proporción de viviendas que cuentan con servicio de recolección de residuos sólidos. Orizaba cuenta con una calificación de 97.5/100, lo cual refleja un buen manejo en la recolección de residuos sólidos y consecuentemente en la cobertura de los servicios de recolección en las viviendas, lo que indica una disminución en las prácticas inadecuadas de disposición de basura por sus habitantes, además de una mejora en el impacto visual de calles y avenidas que lo conforman. El servicio de limpieza pública de la ciudad de Orizaba brinda sus servicios únicamente los días lunes, miércoles, viernes y sábado.

En la Figura 8 inciso "A)" se observa que hay un promedio de más de 10 bolsas por cuadra colocadas para ser recolectadas en su mayoría los fines de semana. Es importante mencionar que los días donde no se recolecta basura las calles se encuentran limpias. Es relevante identificar, por lo menos a nivel muestra, qué días de la semana se utiliza más el servicio de limpia pública, ya que las siguientes figuras, corresponden a diferentes factores de observación en las que se cotejarán los resultados en los días que existe más demanda. En el inciso "B)" se representa el horario promedio en el que los ciudadanos disponen de sus residuos sólidos y anticipa el horario destinado para su colocación y recolección en las zonas designadas. Se observa que casi un $40 \%$ de los residuos sólidos se disponen con dos horas de diferencia a la hora de recolección. En el inciso "C)" se representa a la cantidad de ciudadanos que separa de manera consiente sus residuos sólidos en las categorías de desechos orgánicos e inorgánicos para su recolección. En promedio, solamente el $70 \%$ lo hace. Por el contrario, en contraste con resultados anteriores, se ha observado que incentivar un modelo de separación de residuos sólidos se ha llevado a cabo con un resultado favorable. Por último, en el inciso "D)" se representa que tres cuartas partes de las personas en las zonas observadas depositan anticipadamente su basura en las calles, es decir, antes del horario permitido 
para su disposición en la zona pública (banqueta). Esto significa a nivel de muestra que solo un cuarto de la población coloca sus residuos sólidos a la hora adecuada. Es decir, todavía la cultura ciudadana en este sector tiene deficiencias para poder optimizar el trabajo de los recolectores municipales, y también afecta la imagen de la ciudad como zona turística.

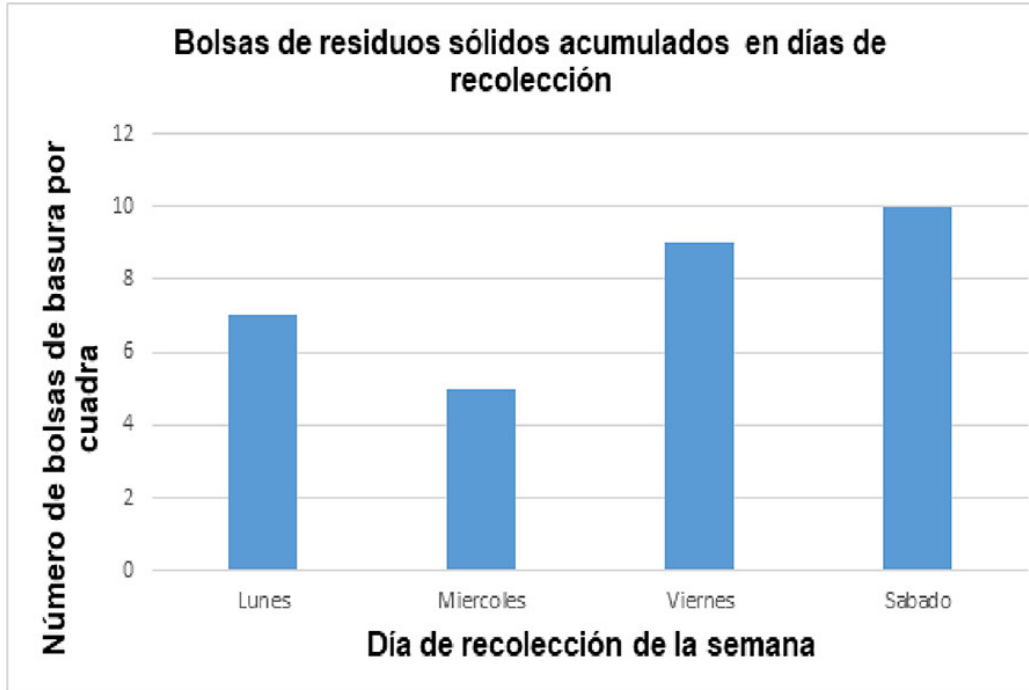

Separación de los residuos sólidos por parte de los ciudadanos en orgánica e inorgánica

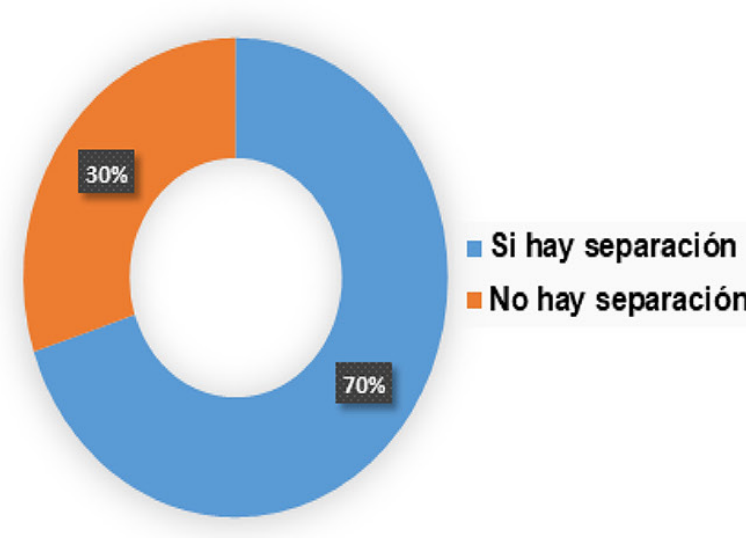

A)

C)
Tiempo de diferencia entre la disposición de basura en la vía pública por parte de los ciudadanos y la recolección de la misma por el servicio de limpia pública

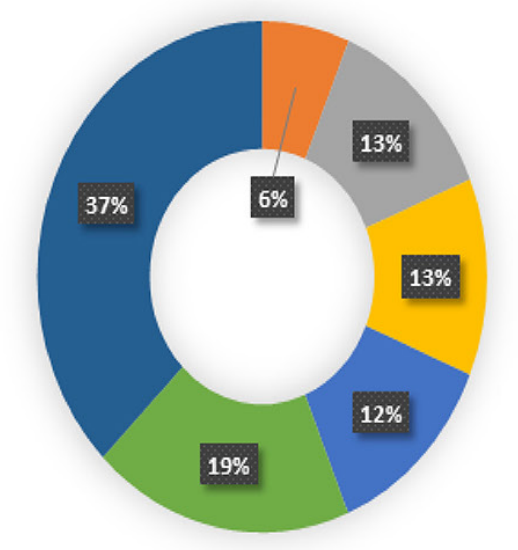

15 minutos

$\llbracket \mathbf{3 0}$ minutos

45 minutos

$\square 1 \mathrm{hrs}$

1:30 hrs

$\square 2 \mathrm{hrs}$

- Más de 2 hrs

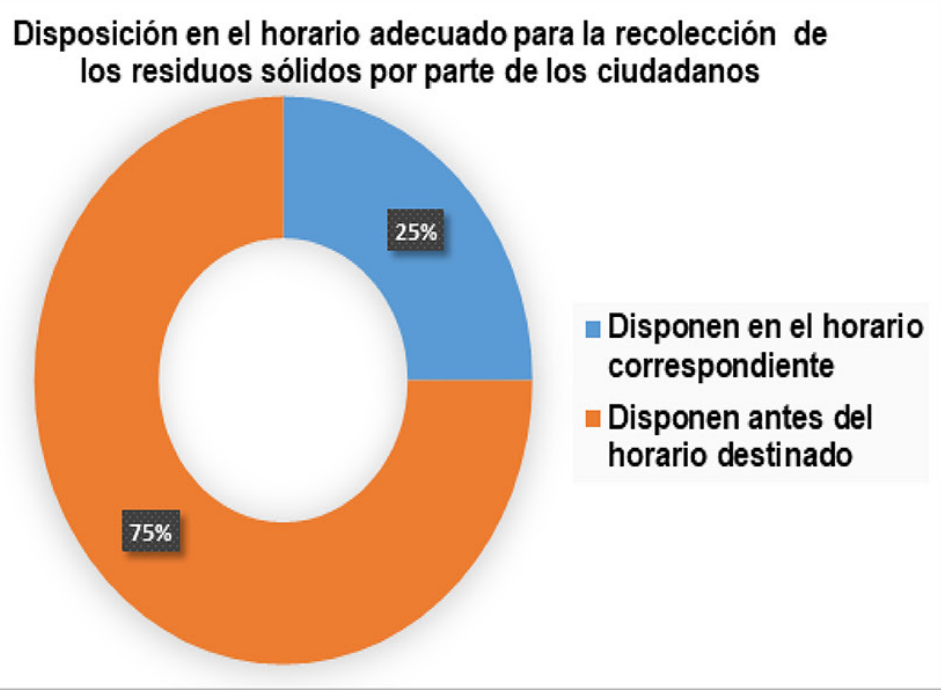

Figura 8. Ejercicio de observación en la ciudad de Orizaba, Veracruz, México, del servicio de limpia pública.

Fuente: Elaboración propia en mayo del año 2020.
En cuanto a la gestión de transporte público:

El transporte público en Orizaba es un tema significativo para la ciudad, pues ha causado polémica entre los habitantes y trabajadores en el área de movilidad urbana. El municipio de Orizaba considera en su PMD que, tanto para una ciudad como para cada región de México, este tipo de transporte debe de ser el transporte primordial en cuanto a uso. Sin embargo, en los últimos años ha incrementado su demanda, ya que un gran número de usuarios lo utilizan todos los días para trasladarse a sus respectivos trabajos o realizar sus actividades cotidianas. El ayuntamiento de Orizaba detectó que, para satisfacer las demandas del crecimiento urbano en constante aumento y que comunique a la ciudad con la periferia y áreas aledañas, era necesario un sistema de transporte público eficiente. Esto con el fin de potenciar la actividad económica de una ciudad, disminuir la necesidad de abordar múltiples viajes e impulsar el uso de modos de transporte diferentes de los que ofrece el sector privado.

Para esto, en el año 2014 el ayuntamiento de Orizaba analizó el sistema de movilidad pública de la ciudad para fines del PMD, determinando que un $76 \%$ de la población total utiliza el transporte público. Sin embargo, un $65 \%$ de los usuarios estaban insatisfechos con el servicio debido al mal estado de las unidades; las emisiones contaminantes, cuya vida útil había sobrepasado el tiempo de utilidad dado o que no se encontraban bajo las reglamentaciones establecidas de manera estatal; tiempo de espera entre rutas y el servicio brindado por los operadores de la unidad. En la parte de inversión económica se detectó que el $30 \%$ del total de los vehículos que conforman la flotilla de autobuses de la ciudad que dan el servicio público necesita renovarse debido al cumplimiento de su tiempo de vida útil (DGTE, 2017).

La red de transporte público estaba conformaba por cinco empresas que brindaban el servicio a través de 173 unidades. Sin embargo, más de la mitad de las manzanas de la zona conurbada de la ciudad, no disponían de servicio de transporte público en ninguna de sus rutas, aun con la existente oferta de unidades y de rutas distribuidas por la ciudad (Ayuntamiento de Orizaba, 2015). Tomando en cuenta estas consideraciones, las propuestas de los funcionarios públicos, en torno al PMD, fueron articular las rutas de transporte público con la planeación urbana deseable. 
Mediante un proceso continuo de la planeación de movilidad, destacan la reorganización de las ahora 244 unidades de transporte público urbano en rutas específicas que reducen la circulación y la planeación direccionada para el ordenamiento vehicular de las unidades de transporte. A su vez, se cuenta con unidades renovadas que generaron una inversión de más de treinta millones de pesos, pero que con ello se reduce hasta en un $37 \%$ anual las emisiones de gases contaminantes realizadas por vehículos, cuya ruta de transporte genera un servicio de calidad a la totalidad de la ciudad (SEFIPLAN, 2017).

En su apartado de "movilidad urbana" el CPI de la ciudad de Orizaba se divide en accidentes de tránsito y longitud del transporte masivo. La primera de ellas arroja resultados acerca de los decesos ocasionados por accidentes relacionados con el transporte público de la ciudad, el segundo evalúa únicamente el desempeño del transporte público masivo de un municipio como lo son trolebuses, tranvías, metro y metro ligero. Debido a que el municipio aún no cuenta con ninguno de estos sistemas de transporte público su calificación no aplica, por lo deja únicamente como resultado un análisis de los accidentes ocurridos en carretera gracias a ello la ciudad obtiene una calificación de 95.4/100, nuevamente una calificación sobresaliente (ONU, 2018).

En la Figura 9 inciso "A)", se representa que, en un periodo de 10 minutos, transitan por lo menos 10 rutas diferentes de autobús (transporte público) que pasan por su respectiva parada, es decir que en la ciudad existe una variedad de rutas y la suficiente infraestructura de este tipo de transporte para cubrir con las necesidades de movilidad de la ciudad. En el inciso "B)" se representa que, el chofer, en la mayoría de los casos $(54 \%)$, no permite el abordaje en zonas no designadas para esta acción, forzando a los interesados a trasladarse a la zona designada y evitando la mala cultura de transporte público. El en inciso "C)" se representa el tiempo promedio que un pasajero espera para abordar la unidad que lo lleva a su destino. En este se representa un tiempo de espera promedio entre 5 y 10 minutos, podemos observar que debido a que las rutas son continúas y abastecen de manera efectiva a la población, esta no sufre de tiempos de espera mayores. Por último, en el inciso "D)" se representa el porcentaje de unidades de transporte público que contaban con verificación vehicular actualizada, emitida por el estado de Veracruz. Certifica que la unidad se encuentra en buenas condiciones en tanto en su infraestructura como con respecto a las emisiones que emana para transitar Figura 9. Ejercicio de observación de Orizaba,
Veracruz, México, del servicio de transporte público.

Fuente: Elaboración propia en mayo del año 2020. dentro de la ciudad. Se puede apreciar que solo un poco menos de un tercio de las unidades de transporte público observadas (33\%) no contaban con una verificación vehicular actualizada y visible para realizar sus operaciones.

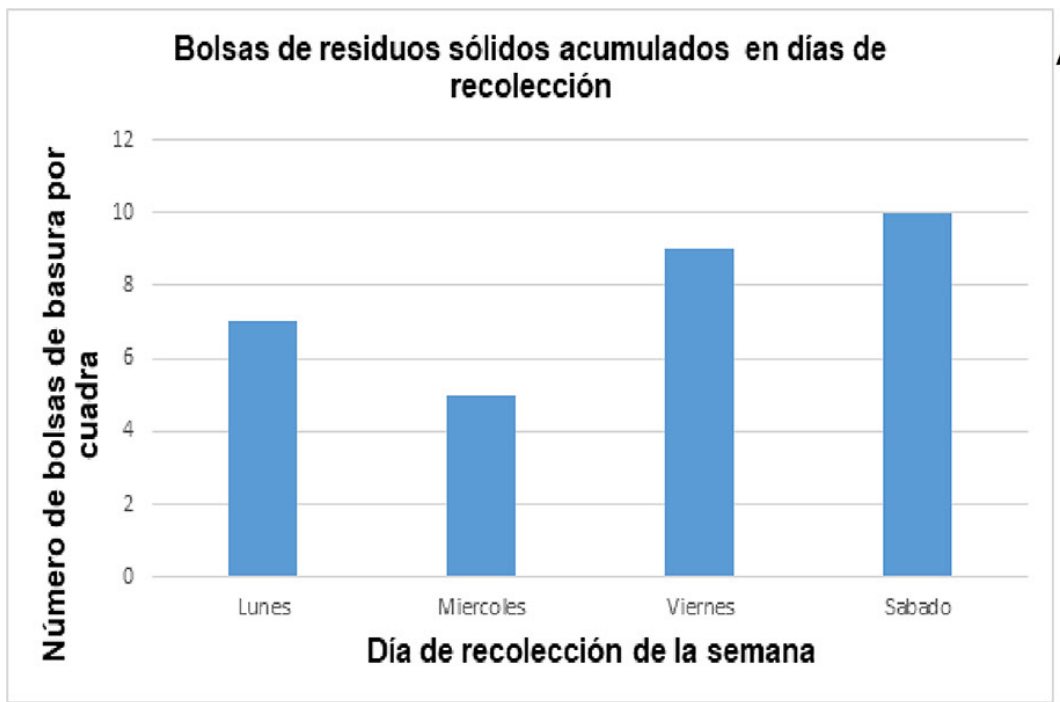

Separación de los residuos sólidos por parte de los ciudadanos en orgánica e inorgánica

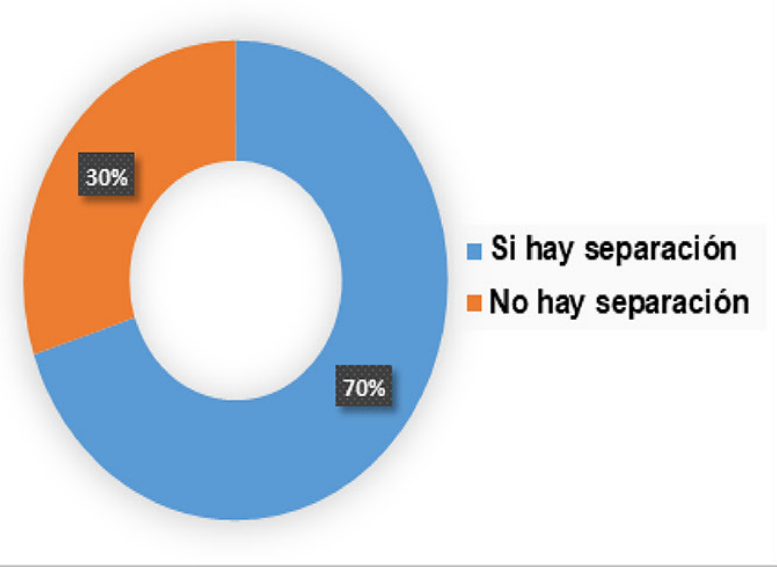

A)

C)
Tiempo de diferencia entre la disposición de basura en la vía pública por parte de los ciudadanos y la recolección de la misma por el servicio de limpia pública

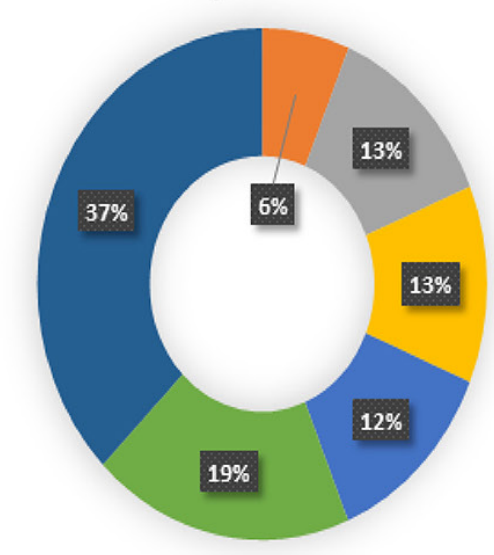

$\square 15$ minutos

$\square \mathbf{3 0}$ minutos

45 minutos

$\square 1 \mathrm{hrs}$

-1:30 hrs

$\square 2 \mathrm{hrs}$

- Más de 2 hrs

Disposición en el horario adecuado para la recolección de los residuos sólidos por parte de los ciudadanos 
En cuanto a la gestión de áreas verdes:

En la ciudad de Orizaba, por muchos años se carecía de una iniciativa para la conservación de áreas verdes dentro de la mancha urbana, pues la estructura se limitó a su territorio sin expandirse a las periferias de la ciudad. Si bien, existían opciones para recreación en los alrededores de la ciudad como la alameda central y el centro recreativo "ExpOri", con la planeación urbana prevista por el PMD, la extensión de la mancha urbana creció de manera desmedida provocando la pérdida de áreas verdes recreativas disponibles al interior de la ciudad (Figura 5).

A partir del año 2015 la ciudad invirtió en la construcción, acondicionamiento y gestión de áreas de recreación ecoturísticas de la cuidad (Ayuntamiento, 2015). Actualmente Orizaba junto con Xalapa cuentan con los parques más distinguidos del estado. Estos son el Paseo del Río y Reserva Animal (Zoológico Orizaba), los cuales constan de 3 kilómetros de área natural, una reserva con más de 250 animales en cautiverio entre los que destacan, cocodrilos, avestruces, jaguares y camellos entre otros. El parque en las faldas del cerro de Escámela es un atractivo donde se realizan actividades como senderismo, además de contar juegos infantiles. Otro atractivo es el "Teleférico de Orizaba", el cual cuenta con 917 metros de largo (el tercer teleférico de mayor longitud en México) brinda de un recorrido de 5 minutos y proporciona una vista temática de la ciudad (SEFIPLAN, 2019).

En la ciudad de Orizaba, casi todos los espacios considerados áreas verdes eran construidos por el hombre. Espacios como parques, jardines, gimnasios al aire libre no permitían que se aprovechara al máximo los privilegios naturales que la zona geográfica proporcionaba a la ciudad. La iniciativa propuesta en los últimos años propició una gestión de planeación, con la que se generaron más de quince nuevas zonas de áreas verdes para la recreación regional y turística. Hecho esto, la ciudad se convirtió en un espacio estético y adornado y, a su vez, los alrededores naturales se convirtieron poco a poco en atractivos turísticos y locales, replicando así las buenas prácticas ejercidas por la ciudad en torno a las áreas verdes para el uso urbano.

Según las últimas cifras del CPI 2018, la ciudad de Orizaba cuenta con una calificación perfecta: 100/100 en su apartado de "áreas verdes per cápita". Lo anterior proporciona información sobre la cantidad de superficie que la ciudad dedica a espacios verdes (bosques, parques y jardines) y si son suficientes para su población con una media óptima internacional de $15 \mathrm{~m}^{2} / \mathrm{hab}$. Sin embargo, si bien es cierto que existen en aumento zonas consideradas como áreas verdes, éstas muchas veces se encuentran descuidadas o en un estado desfavorable para su uso (Figura 10).

Figura 10. Estado de áreas verdes de la cuidad de Orizaba.

Fuente: Elaboración propia en Orizaba, Veracruz, México, en mayo del año 2020

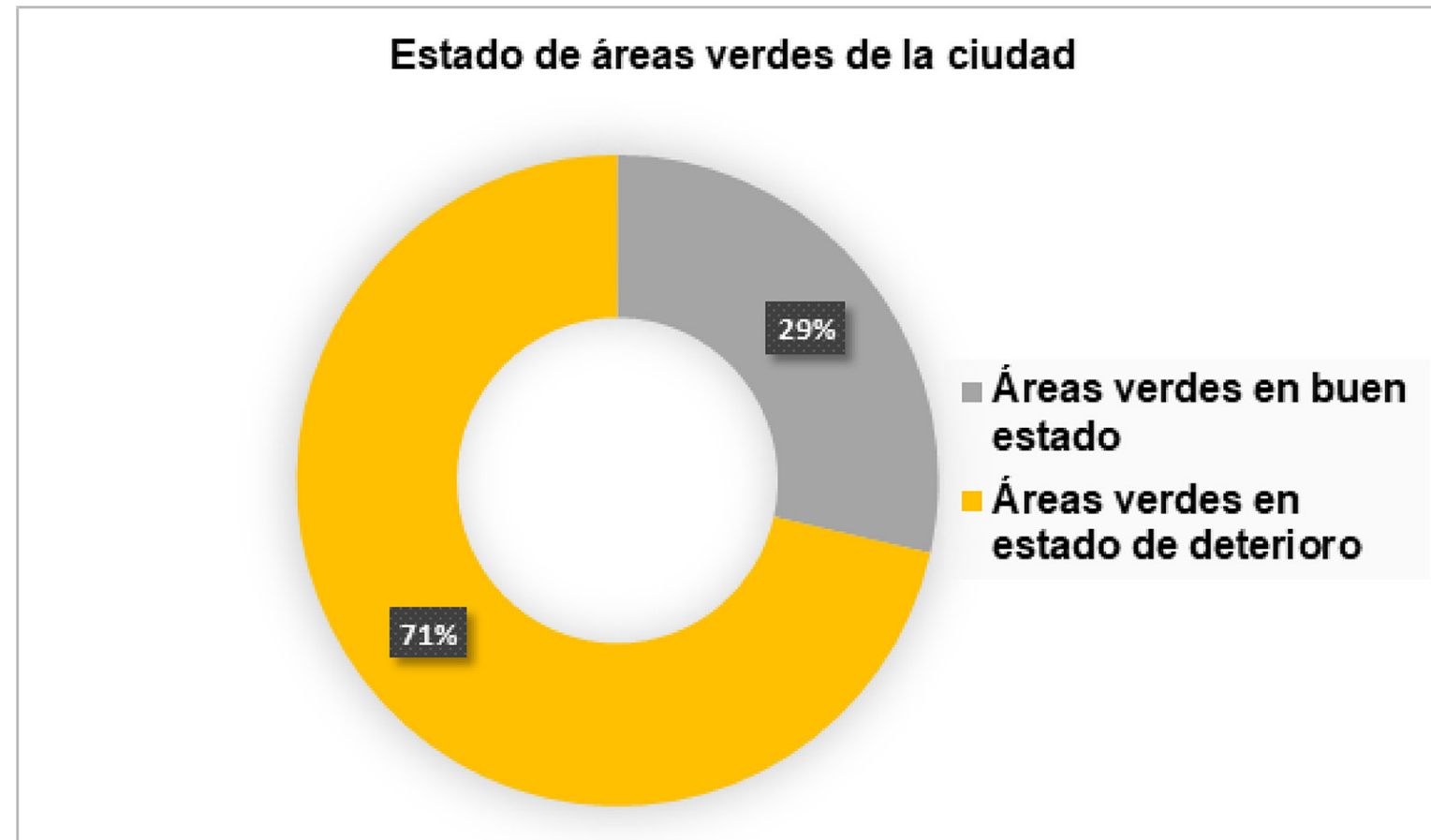

Para el ejercicio de observación se revisaron 40 de las áreas verdes de la ciudad localizadas en los sectores de mayor huella urbana. La Figura 10 representa el porcentaje de áreas verdes, que se encuentran en la zona centro de la ciudad, con un estado de deterioro o no, es decir, cuántas de ellas están cuidadas por la ciudadanía y el gobierno de la ciudad y cuantas no. Se visualiza que casi una tercera parte de las áreas verdes que existen en esta zona se encuentran en un mal estado para su uso. 


\section{Discusión}

La sustentabilidad y la gestión integral de las políticas públicas se han abordado de manera conjunta en los últimos años. Esta intrínseca relación ha fortalecido la generación de conocimientos necesarios, procesos de sistematización y operación con el fin de enfrentar las necesidades y retos a los que nos enfrentamos en la actualidad como sociedad. En este sentido, se requiere de manera urgente fortalecer los lazos entre los procesos de gobernanza y el diálogo entre los organismos gubernamentales, así como también contar con la participación de diferentes actores sociales que permitan transitar hacia la sustentabilidad. Lo anterior constituye un enfoque de planeación en donde se vincule el poder, la política, las instituciones y por supuesto, la sociedad, todo con el fin de gestionar una mejora a las estructuras mismas del escenario en donde se habita, en este caso las ciudades.

El estudio de las políticas públicas en la transición hacia la sustentabilidad genera varias y diferentes áreas de importancia para atender de manera prioritaria. Estas son: la administración pública, los niveles de poder, participación gubernamental y las instituciones que lo conforman; el estudio y análisis de cada escenario epistémico como un estudio único e irrepetible, pero que comparte características comunes establecidas para un fin sustentable; el proceso de planeación, ejecución y evaluación de las políticas públicas; la pertinencia de la participación ciudadana; y su aceptación por parte de la sociedad. Es por esto que, tanto el politólogo como el ecologista urbano, deben de tener un enfoque destinado a la elaboración, planificación, estructuración y evaluación de las políticas públicas implementadas. Es aquí donde las articulaciones institucionales, los tipos de organización existentes en la región, los indicadores analizados y sobre todo las acciones gubernamentales municipales, tienen como finalidad generar la correcta gestión de políticas públicas. Se procura que exista participación, restructuración, corresponsabilidad, transparencia y rendición de cuentas de manera eficaz y eficiente.

En los últimos años, la relación entre la sustentabilidad y las políticas públicas, ha mostrado un trasfondo conceptual metodológico y epistemológico, así como una necesaria dependencia. Deesta manera, ambas disciplinas han logrado generar modelos de aplicación común donde se pueda gestionar la consolidación en los escenarios de interacciones entre los aspectos públicos-municipales que logren una transición hacia una sociedad sustentable. Bajo estos escenarios queda la continua tarea de seguir avanzando en función de construir resultados en materia de política pública que contengan elementos económicos, ecológicos, y sociales, y que dan viabilidad a los proyectos de gestión municipal, encargados de materializar la formulación y aplicación de políticas orientadas al modelo de ciudad sustentable.

Aunque es cierto que los residuos sólidos municipales (RSM), son sólo una parte de los residuos sólidos que genera el país, según cifras de INEGI (2015), éstos generan una cantidad que supera los 102 millones de kilos anualmente. Su recolección, manejo y disposición consumen alrededor de la tercera parte de los recursos invertidos por el sector público, en muchas ocasiones resulta una menor inversión a largo plazo el correcto desecho de estos residuos que la gestión constante, sin planificación de estos para abatir y controlar la contaminación (SEMARNAT, 2011).

Los RSM pueden tener varios efectos ambientales negativos, entre ellos, cuando son vertidos en cuerpos de agua superficiales alteran la estructura física del hábitat e impactan negativamente la calidad del agua y el agua subterránea de los acuíferos se contamina por la infiltración de contaminantes derivados de los residuos que contienen materiales tóxicos depositados. Los residuos también afectan la calidad del aire, ya que están asociados frecuentemente a la generación de malos olores y esto genera impactos en el sector turístico, en la biodiversidad de la zona, así como en la producción de humos, gases y partículas en suspensión por la quema intencional o espontánea de la basura. Por otro lado, la presencia de vectores (ratas, cucarachas e insectos) asociados a los tiraderos aumenta la transmisión de enfermedades como el cólera, disentería, y amebiasis, entre otras (SEMARNAT, 2011).

De acuerdo con los requerimientos mínimos establecidos por la organización Mundial de la Salud debe de haber un mínimo de 9 metros cuadrados de áreas verdes por habitante 
(López, 2013). Sin embargo, las dimensiones y características de los municipios y metrópolis de México hacen que la falta de áreas verdes sea especialmente evidente y las oportunidades de ampliarlas son realmente escasas, según las condiciones de cada zona. La falta de planeación en el crecimiento de las zonas urbanas pone en riesgo su permanencia y estado de conservación (Sunkel y Gligo, 1980). Actualmente, la apuesta por las áreas verdes se ha centrado en mejorar la calidad de las existentes realizando para ellas proyectos de remodelación o recuperación, pero en muy pocos casos podemos observar la gestión de áreas verdes en una zona urbana ya planificada. En muchos sentidos, el reto de los arquitectos paisajistas está en enfrentarse a intervenir en proyectos que incluyen la expansión de la ciudad a la periferia, teniendo esta un mínimo de impacto frente a la inmensidad de la huella urbana que esta expansión conlleva (Buzai, 2018).

En cuanto a la problemática del transporte público es sabido que América Latina, por ser una de las regiones con mayor urbanización y motorización a nivel global, reporta una gran crisis de transporte público. Teniendo en cuenta que los costos del congestionamiento vial para una ciudad representan cada año un enorme gasto económico para la ciudadanía, la búsqueda de soluciones para disminuir su impacto es de suma importancia. Así, para mantenerse tanto competitivas como habitables, las ciudades han optado cada vez más por alternativas de transporte público. Cada ciudad considera sus necesidades y con base en ello gestiona su modelo de movilización urbana, casi siempre optando por métodos alternativos al transporte privado por automóvil (Negrete y Paquette, 2011).

Desde una perspectiva general, la participación ciudadana puede limitar su actuación a aquellos casos en los que se detecta una respuesta de acción colectiva de la sociedad a una invitación realizada por parte de las autoridades gubernamentales para así influir (con éxito o no) sobre las decisiones de la agenda pública de la localidad (Balbis, 2005). Sin embargo, la participación ciudadana es una destreza que difícilmente está tomando fuerza en la práctica. En un sentido técnico, es concebida como un proceso de desarrollo social, incesante y emprendedor, por el cual los miembros de una entidad, a través de mecanismos establecidos y organizaciones legítimas en las cuales se desenvuelven (que deberían ser apoyadas por el gobierno) aportan y participan en favor del bien común para aplicar o no políticas de intervención pública en su territorio (Fuentes, Buschiazzo y Castillo, 2016).

Así, la participación ciudadana es un componente indicador y un elevador de la calidad de vida, un elemento civilizador que lo compone el sector social. Además de esto, es capaz de crear conciencia y socializar a quienes forman parte de ella. La presencia de los ciudadanos en los asuntos públicos es y siempre ha sido una condición necesaria para alcanzar la gobernabilidad democrática. A medida que el ejercicio del poder está más legitimado en la voluntad obtenida a través de un consenso social, mayores son las posibilidades de visibilizar las aspiraciones de los diferentes sectores sociales (Norris, 2002).

\section{Conclusiones}

Dado el crecimiento demográfico y las necesidades que demanda la sociedad, los recursos en las ciudades son cada vez más limitados, por ello es necesario atender con urgencia la creación y aplicación de soluciones colaborativas entre las instituciones y la sociedad en general. El aumento de la relación entre las políticas públicas y las prácticas participativas de la sociedad tiende a incrementarse, debido a que, para resolver los problemas cada vez más complejos y rendir cuenta de los resultados, un solo organismo no podría resolver por sí solo estos problemas sociales-gubernamentales.

Ya sea en la cuestión práctica como en la teoría de la administración pública, la gestión de políticas públicas de manera participativa es una respuesta a la influencia ejercida desde el lado de la ciudadanía para cubrir ciertos déficits de implementación efectiva de gobernabilidad. Un punto crucial para que su efectividad sea plausible es que, tanto las políticas como la participación en estas, deben de estar arraigadas a las necesidades y aspiraciones de los ciudadanos para efectos de su eficacia. Cabe señalar que, para 
la correcta gestión de políticas públicas se requiere de investigación, un proceso de planeación, experiencia de los involucrados, así como la contribución y participación de la ciudadanía.

En relación con los documentos oficiales de la ciudad y los resultados del CPI emitidos en comparación con el ejercicio de observación realizado, se demostró que la ciudad aumentó su número de áreas verdes para satisfacer a sus habitantes, eso se demostró mediante la evaluación realizada que arrojó resultados positivos junto con una calificación alta. Sin embargo, el indicador solo mide la cantidad existente, no mide la calidad de estas áreas verdes, muchas de las cuales se encuentran en malas condiciones, tanto en sus instalaciones como en el cuidado del terreno. Según el indicador de residuos sólidos, Orizaba expone en sus cuadernillos municipales una mejora en la recolección de residuos, además de contar con vehículos para facilitar su manejo, aunque se observó que la cultura de reciclaje que toma en cuenta la disposición final, la separación adecuada en horarios específicos y de manera ordenada, aun deja que desear.

Por otra parte, Orizaba cuenta con un número suficiente de unidades de transporte público, como lo son camiones de pasajeros. Estos generan un caos vial a la hora de llevar a cabo sus rutas, debido a la falta de señalización para el abordaje y descenso de pasajeros o simplemente el hecho de que sus transportistas hacen caso omiso de ellas. Orizaba muestra que el número de transportes públicos aumentó a medida de la puesta en marcha de su PMD, sin embargo, que aumentara el número de transportes públicos para satisfacer a la ciudadanía no garantiza una correcta cultura vial. Cabe destacar que el indicador del CPI no mide estos rubros para considerar la sustentabilidad de una ciudad.

Por lo anterior, se enfatiza que, para lograr una eficaz interrelación técnica entre consideraciones sociales y democráticas hay que tener en cuenta procedimientos y arreglos complejos para que estos puedan definirse y llegar a su mejor implementación posible. También hay que incorporar elementos evaluativos, de selección y afinación para estipular criterios que resulten indicados al atender problemáticas especificas según contexto geográfico, social, cultural, y a su vez, implementar vías de solución para la motivación de la participación social en las políticas públicas.

\section{Referencias bibliográficas}

Apablaza, M. C., y Ruiz, C. H. (2010). Planificación territorial y crecimiento urbano: desarticulaciones y desafíos de la sostenibilidad urbano-regional en Santiago metropolitano. Scripta Nova. Revista Electrónica de Geografía y Ciencias Sociales, 14(26), 44-61.

Ayuntamiento de Orizaba. (2018). Limpia Pública y Ecología. Recuperado de: http:/l www.orizaba.gob.mx/Dependencias/Limpia-p\%C3\%BAblica\#

Ayuntamiento de Orizaba. (2015). Reglamento de Parques y Jardines para el Municipio de Orizaba, Veracruz. Recuperado de: http://transparencia2014.orizaba.gob.mx/ wp-content/uploads/2015/12/fraccion $\% 201 \% 20$ Marco\%20Juridico/Reglamentos/ Reglamento\%20de \%20Parques \%20y\%20Jardines \%20Para \%20 el\%20 Municipio\%20de\%200rizaba.pdf.

Ayuntamiento de Orizaba. (2015). Servicio de Transporte Público en Orizaba. Recuperado de: https://serviciodetransporte.net/transporte-publico/veracruz/ orizabal

Baca, J. C. (2014). Indicadores de Ciudad Sostenible. Distrito Metropolitano de Quito: Secretaría de Ambiente.

Balbis, J. (2005). Participación e Incidencia Política de las OSC en América Latina. Recuperado de: http://equipopueblo.org.mx/part_inci_alop.htm.

Buzai, G. D. (2018). Crecimiento urbano y potenciales conflictos entre usos del suelo en el municipio de Luján (Provincia de Buenos Aires, Argentina).: Modelado espacial 2016-2030. Cuadernos geográficos de la Universidad de Granada, 57(1), 155176. 
Barton, J. R. (2016). Sustentabilidad urbana como planeación estratégica. EURE Revista Latinoamericana de Estudios Urbano Regionales, 33(96), 27-45.

Fuentes, G., Buschiazzo, V., y Castillo, M. (2016). ¿Quiénes, cómo y para qué? Los espacios de participación convocados por el Ministerio de Desarrollo Social uruguayo. Espiral (Guadalajara), 23(65), 89-121.

CEPAL. (2007). Indicadores ambientales y de desarrollo sostenible: avances y perspectivas para América Latina y el Caribe (Primera ed.). Santiago de Chile: Naciones Unidas: Manuales.

DGTE. (2017). Programa de reordenamiento y regularización del transporte público de Veracruz 2017. Dirección General de Transporte del Estado. Tomado de http:// transporteveracruz.gob.mx/Orizaba

López, E. (2013). Beneficios en la implementación de áreas verdes urbanas para el desarrollo de ciudades turísticas. Revista de arquitectura, urbanismo y ciencias sociales, 4(4), 23-36.

González Reynoso, F., y Maldonado Meza, L. (2008). Leyes de Participación Ciudadana haciendo el señalamiento cuando este tema es tratado en las Constituciones Estatales. Revista Plural, 16(4), 45-74.

Hernández, I. A. (2019). Proyectos estratégicos y gobernanza metropolitana. Nuevo Aeropuerto Internacional de la Ciudad de México, 2001-2019.

INEGI. (2010). Cartografía geoestadística urbana, Cierre del Censo de Población y Vivienda 2010. Orizaba. Recuperado de: https://www.inegi.org.mx/app/biblioteca/ ficha.html?upc=702825681241

INEGI. (2015). Residuos Sólidos. Obtenido de Instituto Nacional de Estadística y Geografía. https://www.inegi.org.mx/temas/residuos/

INEGI. (2018). PIB y cuentas nacionales. Instituto Nacional de Estadística y Geografía. https://www.inegi.org.mx/temas/ee/

Jardinez, A. J. (13 de febrero de 2019). Panorámica Orizaba. Recuperado de: http:// gigapan.com/gigapans/149761.

Navarro, J. C. (28 de mayo de 2020). Méxicoas. Recuperado de: https://mexico.as.com/ mexico/2020/05/28/tikitakas/1590694646_937936.html.

Negrete, M. E., y Paquette, C. (2011). La interacción entre transporte público y urbanización en la zona Metropolitana de la Ciudad de México: un modelo expansivo que llega a sus límites. Territorios, 44(25), 15-35.

Norris, P. (2002). La participación ciudadana: México desde una perspectiva comparativa. Facultad de Gobierno John F. Kennedy. Universidad de Harvard, Cambridge.

Quiroz, B. D. (2018). Evaluación de la vulnerabilidad social con indicadores censalesaplicación al área metropolitana de Lima y Callao.

Requena Ruiz, I. (2011). Arquitectura adaptada al clima en el movimiento moderno: Le Corbusier (1930-1960).

Rodríguez, C., y Flores, A. (2009) El Sistema Nacional de Indicadores Ambientales (SNIA). En J. López Blanco y M. de Lourdes Rodríguez Gamiño (coods), Desarrollo de indicadores ambientales y de sustentabilidad en México. México: Instituto de Geografía, UNAM. Recuperado de: http://www.publicaciones.igg.unam.mx/index. php/ig/catalog/view/12/12/34-1

Rodríguez, A. S. (2015). La participación ciudadana en México. Estudios Políticos, 34, 93-116.

Satterthwaite, D. (1993). Problemas sociales y medioambientales asociados a la urbanización acelerada. Revista EURE-Revista de Estudios Urbano Regionales, 19(57), 79-84.

Olvera, A. (2007). Notas sobre la participación ciudadana desde la óptica de las OSC, México. Mexico: Incide Social. 
ONU. (2018). Índice Básico De Las Ciudades Prósperas. Orizaba Veracruz: ONUHABITAT.

Orizaba, H. A. (2014). Plan Municipal de Desarrollo Orizaba, Veracruz 2014-2017. Orizaba Veracruz: Orizaba Ayuntamiento.

SEFIPLAN. (2017). Sistema De Información Municipal- Cuadernillos Municipales. Orizaba Veracruz México: Gobierno del Estado.

SEFIPLAN, 2019). Cuadernillos Municipales. Orizaba: Veracruz, Gobierno del Estado.

SEMARNAT. (2011). Minimización y manejo ambiental de los residuos sólidos. México: INE-SEMARNAT

SEMARNAT, (08 de septiembre de 2020). Indicadores Básicos de DesempeñoAmbiental en México, SEMARNAT. Recuperado de: https:/lapps1.semarnat.gob.mx:8443/ dgeia/indicadores14/conjuntob/00_conjunto/marco_conceptual.html

Sunkel, O. y Gligo, N. (1980). Estilos de desarrollo y medio ambiente en la América Latina. Ciudad de México: Fondo de Cultura Económica.

Vargas Azuero, N. A. (2013). Diagnóstico de sostenibilidad para valorar la gestión de responsabilidad social (RSE) en las pymes del Distrito Metropolitano de Quito Subsector c1070-c1080: elaboración de productos alimenticios (Bachelor's thesis).

Viso, A. M. (2005). Sostenibilidad y gobernanza. Arbor, 181(715), 317-331. 